\section{EL DIARIO DE ADÁN Y EVA DE LA MANO DE MARK TWAIN} Y GIOCONDA BELLI

ADAM AND EVE'S DIARY BY MARK TWAIN AND GIOCONDA BELLI

María Caballero Wangüemert Universidad de Sevilla

Resumen:

Abstract:

Dado que en Europa prevalece la tradición Due to the fact that the Judeo-Christian cultural judeocristiana, las alusiones a Adán tradition prevails in Europe, there are plenty y a Eva posteriores a la Biblia son muy of references to Adam and Eve after the Bible. abundantes. En este artículo se presentará un In this article we will expose an analysis about análisis de cómo aparecen estas dos figuras en how these characters are represent in the la obra de Gioconda Belli y Mar Twain desde work of Gioconda Belli and Mark Twain from un punto de vista antropológica. Este estudio an anthropologic point of view. This study is es interesante porque ambas obras ofrecen interesting becaus both work offer different es interesante porque ambas obras ofrecen interesting because both works offer different
dos perspectivas completamente distintas del perspective of the Biblical myth. mito bíblico.

\section{Palabras claves:}

Adán, Eva, Mark Twain, Gioconda Belli.

\section{KEY WORD:}

Adam, Eve, Mark Twain, Gioconda Belli.
Musulmanas, judías y cristianas, un sintagma que, evidentemente, apela a los conceptos "mujer y religión", en el marco de la libertad del denominado "sexo débil", y de los continuos debates agigantados tras la conferencia de Pekín (1995). ¿Es la religión una traba para la mujer, impide su desarrollo personal? O, por el contrario, ¿apuesta por ella como persona humana, complemento indispensable y no supeditado al varón para construir nuestra sociedad del XXI? Tengo mi opinión al respecto, basada en trabajos sobre la mujer en el catecismo de la Iglesia Católica (Caballero: 1996), una Iglesia que cometió sus deslices -como todas- pero que rescata el papel prioritario de la mujer en la creación de nuestro mundo cotidiano, que habla de la necesaria "feminización" de la sociedad como único camino para salir de la deshumanización en que nos movemos. Aun así, y teniendo en cuenta la cantidad de teólogas participantes en el congreso, no quise orientar mi trabajo por esos derroteros. Se me ocurrió más bien volver los ojos a la mujer primigenia, Eva, la primera mujer según el "Génesis", ese libro iniciático de la Biblia, que ha marcado nuestra cultura occidental. Y hacerlo desde la literatura. Para ello, convencida de que el tema habría sido ya tratado y deseando contextualizar mi presentación, me lancé a google. No hay más que marcar "Adán/Eva novela" y la búsqueda aporta al abrumado e inocente investigador más de 134.000 entradas. ¿Por qué tal éxito? Uno especula, con esa filosofía de andar por casa avalada por la formación literaria, y concluye que en todos los tiempos y culturas el hombre quiso inquirir acerca de sus orígenes, del sentido de su vida. No se resignó a no saber. Si a eso unimos que Europa es culturalmente grecorromana y judeocristiana, no sorprenderá encontrarse con la Biblia, el libro de los libros incluso para agnósticos como J.L.Borges. Que, como es bien sabido, se abre con el "Génesis", arranque de la historia de la humanidad cifrada en la escritura. Ese relato (creación, pecado y culpa) con la subsiguiente pérdida del mítico paraíso, fascinó a los hombres; escritores como Milton -Paradise Lost (1658)dieron fe de ello. Ese relato, que pesa todavía hoy en el subconsciente colectivo, ha lastrado a la humanidad que desde siempre planteó la utopía como un retorno a los orígenes, al paraíso perdido. Por lo que se refiere a Hispanoamérica, Ainsa (1977) y un largo etcétera escribieron sobre la utopía como motor de la conquista americana, como proyección de las mentes europeas desde el humanismo -Moro, Utopía (1518); bien sean "ínsulas" virginales, misiones jesuíticas, o las utopías socialistas del XIX -falansterios y demás, marxismo y su cielo en la tierra... etc. El tema retorna una y otra vez a la novela: Eça de Queiroz (1930), López de Haro (1939), Jean Effel/Camilo José Cela (1968), Fco Muñoz (2006)... incluso una notable escritora, Amélie Nothomb acaba de presentar en marzo su última novela titulada Ni de Eva ni de Adán (2009). Por no hablar del cine, que dejo aparte pero obviamente también lo trató.

Por ello, cuando Mercedes me urgió a traer algo a este congreso recordé la presentación el pasado curso en mi Facultad de Filología de El infinito en la palma de la mano (2009). Una novela escrita por Gioconda Belli (1948), nicaragüense, nacida en 
Managua, mujer comprometida con su país, beligerante sandinista y militante del Frente de Liberación Nacional lo que le llevó al exilio mexicano y costarricense hasta la caída de Somoza. Desempeñó diversos cargos en el gobierno revolucionario, una vez tomado el poder en su país, hasta el distanciamiento con Daniel Ortega que de nuevo la lleva al exterior (Santa Mónica y Los Ángeles en Estados Unidos), en un paralelismo que habría que matizar con Isabel Allende y otras. Formada en la izquierda, en un país con poetas de claro compromiso religioso y político como Ernesto Cardenal, confiesa admiración por Coronel Urtecho a quien dedica Waslala (1996), la tercera de sus novelas tras La mujer habitada(1988) y Sofía de los presagios (1990), que obtuvieron inmenso éxito de ventas. No obstante, su actividad de narradora sucedió a una larga vida de poeta consagrada por varios premios: Sobre la grama (1974), Línea de fuego (1978, Premio Casa de las Américas), Truenos y Arcos iris (1982), Amor insurrecto (1984), De la costilla de Eva (1986), El ojo de la mujer(1991)... Esta, por el momento última novela, viene avalada por el prestigio de un premio: el 50 Biblioteca Breve, el mítico premio de Seix Barral que revalidara en su momento a ciertos autores del boom hispanoamericano como Vargas Llosa o Fuentes; un premio también obtenido por Volpi con su novela En busca de Klingsor. Y lo señalo porque Volpi es uno de los componentes de ese nunca del todo fraguado segundo boom editorial.

En resumen, un premio bien pagado y con renovado prestigio para una visión femenina/feminista no sólo del pecado original sino de los primeros tiempos de la humanidad. En ese sentido, parecería reelaboración intratextual de su poemario $D e$ la costilla de Eva. Y lo es por la toma de postura: es la mujer quien lleva la batuta, el mundo sale de su costilla y se constituye día a día través del amor y la guerra, del eros y la actitud combativa, revolucionaria y solidaria. No en vano, el poemario pertenece a una etapa anterior, más "comprometida" en el tópico sentido del término y cuyo centro en el librito sería el poema "Reglas del juego para los hombres que quieran amar a mujeres", especie de código de conducta en XI capítulos del que destacó por su representatividad el VIII:

"El hombre que me ame reconocerá mi rostro en la trinchera rodilla en tierra me amará mientras los dos disparamos juntos contra el enemigo" (Belli: 1986, 42).

Aun así, muchos versos enlazan con la futura Eva de El infinito en la palma de la mano. Por ejemplo, éste de "Vigilia": "Soy yo la que construye esperanza sobre la hierba" (Belli: 1986, 37). E incluso "Problemas de la transición", un poema de amor contextualizado, nombra Adán y el paraíso, anticipando lo que reelaborará temáticamente años después:

“Quizás pensamos que ya nunca estaríamos solos

Imaginar paraísos es más fácil que construirlos

- también menos hermoso-

pero henos aquí contabilizando noches de soledad (...).

Amo a un hombre.

Sé que él me ama,

pero grandes soledades y distancias que mi mano no alcanza

nos separan

y así sigo viviendo $(.$.

odiando la soledad

odiando la soledad

gual que Adán cuando vagaba solo y ansioso

por el paraíso terrenal" (Belli: 1986, 77-78)

En la novela del 2008 será el amor el único paliativo a la pérdida del paraíso, el remedio contra la soledad sentida más intensamente por el hombre; para la mujer es dura, pero ella la contrarresta con su cercanía al mundo natural.

De otro modo más sutil pero no por ello menos verdadero, reelaboración intratextual de Waslala: memorial del futuro, porque es la utopía, el eterno dilema civilización/ barbarie, el viaje de la nueva especie por una naturaleza madre y madrastra a la que se enfrenta una y otra vez la creatividad del ser humano, lo que subyace en esta nueva novela. Una vez más, la contextualización y el compromiso de la primera etapa de Gioconda se plasman en el testimonio y la denuncia contra los vertidos tóxicos del planeta en concretas regiones del Nuevo Mundo; aunque -como escribí hace años-, “el emblema del río (es) símbolo de ese viaje interior, iniciático, de un personaje femenino que anhela obsesivamente alcanzar el paraíso utópico, el lugar de eterna primavera -Colón dixit- que se esconde tras el corredor de los vientos, inevitable umbral mítico. La Utopía de Moro, Ulises el eterno viajero, Platón y sus atisbos sobre la función del poeta en la sociedad...Toda la tradición occidental transferida al Nuevo Mundo se procesa en una búsqueda de cuño autobiográfico" (Caballero: 2003, 115).

En gran medida, ése es el trasfondo de la nueva novela, más despojada de cultura, más ligada a la naturaleza, como corresponde a un mundo primigenio. Pero Eva no es un simio, un chimpancé; es un ser humano que razona y pondera... un ser humano equilibrado -más de lo creíble-, que le da vueltas al sentido de la creación, a su identidad personal y futuro. Veleidades de la ficción que puede permitirse anacronismos sin límite.

\section{DOS NOVELAS, DOS ÓPTICAS: MODERNIDAD/POSMODERNIDAD}

A la hora de trabajar ese tema de Adán/Eva y su paraíso, pensé que podría ser instructivo contraponer esta novela al texto de Mark Twain, El diario de Adán y Eva, escrito en 1892 y siempre de moda: acabo de encontrar una entrada en Internet sobre texto y autor; de constatar también el éxito de la versión teatral que Blanca Oteiza y Miguel Ángel Solá estrenaron en el Teatro Reina Victoria de Madrid (enero del 2006) con representaciones durante más de dos años... A la hora de enfrentar los dos textos me guiaba una serie de inquietudes que, de momento, voy a sintetizar en 
dos preguntas: ¿podría hablarse de versión masculino-patriarcal frente a la mirada femenina? La segunda, más literaria, tiene que ver con la reelaboración intertextual: si Gioconda vive en los Estado Unidos -pensé- con seguridad ha leído a Twain. Y, ¡bingo! últimamente lo he visto confirmado en sus declaraciones (Belli: 2008a, 4) Estamos ante dos textos muy distintos -uno fresco y gozoso, otro desencantadopero, curiosamente, con puntos en común. Por lo que se refiere a la estructura, está mucho mejor fraguada la novela de Gioconda, pensada, dialogada y escrita desde la óptica femenina. Se trata de un relato bien desarrollado en 31 capítulos, que arranca de la primera sensación de Adán y se cierra con la muerte de su hijo Abel, desventura máxima ya que con ella entra la muerte en el universo. Las claves: el dolor, la injusticia de un mundo al que somos enviados sin comerlo ni beberlo. Lo positivo: el amor de la pareja y la tarea de hacer la historia, aventura apasionante. La caída aparece muy pronto y la novela se centra en el arranque de la historia de la humanidad, todo ese mundo de sensaciones (el día y la noche, la lluvia/la nieve, las estaciones, cómo y de qué alimentarse, la complementariedad de la pareja, desde la supremacía de ella, más sosegada e inteligente, en misterioso contacto con las fuerzas de la naturaleza y los animales de los que aprende, incluso a parir...) que les rodeará en adelante. El pecado rompe la armonía: no entienden el lenguaje de los animales, que ahora les atacan, deben luchar duro para sobrevivir. Por el contrario, Twain, siempre obsesionado con la Biblia, nos da un texto fragmentario en primera persona, El diario de Adán y Eva, que contiene (2005):

\subsection{Diario de Adán (1893, The Niagara Book) (pp. 11-34), en primera persona.}

3.2. Diario de Eva (pp.37-68, con una cuña en cursivas pp.56-59), de nuevo en primera persona, es la otra versión de la jugada, su polo opuesto

3.3. Autobiografía de Eva, que curiosamente se abre con fragmentos de su diario (pp. 71-127), abarcando de modo amplio aunque con elipsis temporales los tres primeros años de su vida; luego hay breves referencias a los 4-5, 10, 15... Habría que decir que en absoluto es una autobiografía según la poética actual (Lejeune: 1975 y 1998; De Toro/Gronemann: 2004; Pozuelo: 2006), es decir, el relato de acontecimientos digeridos y asimilados desde un yo integrador que escribe consciente de todo.

3.4. Diarios anteriores al diluvio: pasaje del diario de Satanás (pp. 131-140). Relato de la tentación y caída, en plan sumario/escenas dialogadas desde el punto de vista de la serpiente que lo abre en primera persona.

3.5. Pasaje del diario de Eva (pp. 141-146) en el que se nos cuenta la expulsión del paraíso hasta la muerte de Abel y entrada de ésta en el mundo. Estamos ante un sumario en primera persona de plural que enlaza con el final del relato de Satanás.
3.6. Fragmentos del diario de Adán (1905, reescrito y corregido por el autor y nunca publicado en vida) (pp. 149-169). Abarca desde que visualiza a Eva, la nueva criatura, hasta que los chicos cumplen diez años, tras la caída y expulsión. Es una versión más sintética, incluso han desaparecido algunas entradas del diario.

Texto frustrado en su momento desde el punto de vista estructural, con problemas de publicación (nunca vio la luz en vida del autor como novela); se recupera hoy en día con las nuevas teorías posmodernas y se valora el perspectivismo (Adán/Eva/ Satanás), tan importante desde la "generación perdida". El mismo suceso se enfoca, enriqueciéndolo, desde ópticas complementarias u opuestas. Adán es el más inmaduro y en su caracterización confluyen todos los tópicos desde la óptica irónica y burlesca, muy divertida de M. Twain. Habla así desde la primera página:

“Esta nueva criatura de pelo largo me está estorbando mucho. Está siempre rondando y siguiéndome por ahí. No me gusta eso. No estoy acostumbrado a la compania. Ojalá se quedara con los otros animales (...). No consigo ninguna oportunidad de poner nombre a nada. La criatura nueva pone el nombre a todo lo que se acerca antes de que pueda ni protestar" (Twain: 2005, 11-12)

Ni que decir tiene que el texto invierte el relato bíblico donde es el varón quien organiza la creación y da nombre a los seres, a imagen y semejanza divinas. La mujer ha tomado el poder; Twain acusa el sufragismo norteamericano del XIX, se mueve desde los parámetros patriarcales, pero, como varón, asume las incipientes críticas a la futura revolución femenina. En su texto, Adán no necesita la compañía femenina no padece de soledad sino más bien lo contrario: "Me contó que estaba hecha de una costilla extraída de mi cuerpo. Eso es al menos dudoso" -comenta (p.19) intentando poner distancias-. Desde su punto de vista, la loca es ella:

"Ahora se ha hecho amiga de una serpiente. No tiene problemas con los animales. Confía en todos (...). Dice que la serpiente le aconseja probar la fruta de ese árbol y que eso nos brindará una magnífica educación, noble y selecta. Le dije que también nos proporcionaría otra cosa... que introduciría la muerte en el mundo. Fue un error... habría sido mejor guardarme la observación. Solo sirvió para darle una idea: podría salvar al buitre enfermo y suministrar carne fresca a los abtido abatidos haría. Preveo problemas. Emigraré" (Twain: 2005, 20-21).

Un último aspecto interesante en el diario de Adán: su lejanía, como símbolo de no-participación en la famosa culpa, escamoteada en su relato y visualizada por sus consecuencias: el estallido y desorden universal de la creación. En contra del relato bíblico, Adán escapa del paraíso antes del pecado, para zafarse de Eva quien, inexorablemente le buscará y ofrecerá manzanas. La habitual ironía de Twain se convierte en cinismo en el relato de su personaje: 
"En realidad no lamenté que viniera porque aquí no hay más que pobres deshechos y ella trajo algunas de esas manzanas. Me vi obligado a comerlas, tenía tanta hambre. Iba contra mis principios, pero veo que los principios no tienen verdadera fuerza salvo cuando uno está bien alimentado" (Twain: 2005, 22).

Sin comentarios! Eva es la más reflexiva, madura e inteligente: es ella la que nombra las cosas para que él no trabaje y no se dé cuenta de sus limitaciones. Es ella quien inventa el fuego, quien hace experimentos, quien está más cerca de los animales y la naturaleza... es ella quien persigue al hombre, corroida de soledad, y no entiende que la rechace y no la quiera... es ella quien reflexiona acerca del por qué de su amor y del sentido de su creación. Es aquí donde aparecen las grandes diferencias con la novela de Belli, porque, aunque Eva se sabe superior, esta concesión de Twain se enmarca en un planteamiento patriarcal:

"Entonces ¿por qué le amo? Simplemente porque es del género masculino, supongo (...). Es fuerte y apuesto, y le amo por eso, y le admiro y estoy orgullosa de él pero podría amarle sin esas cualidades. Aunque fuera vulgar le amaría, aunque estuviera hecho una ruina le amaría, y trabajaría para él, y me esclavizaría por él y rezaría por él y velaría junto a su cama hasta que me muriera" (Twain: 2005, 66-67).

¡Qué bella declaración de amor! Porque el amor es libre, es un don, uno se da porque quiere y para siempre... Supongo que las feministas de todos los tiempos se rasgarán las vestiduras al leerlo, pero si es recíproco, merece la pena. Nada igual encontraremos en Gioconda, aunque su Eva sea también incondicional de Adán. ¡Sorpresas que da la vida, la vida que da sorpresas! Por el momento, y retornando a Twain, la autobiografía de Eva reelabora de nuevo el primer año de Eva en el mundo hasta que encuentra a su Adán, su primer y airado rechazo (p. 95) y todo el proceso de petición de perdón y enamoramiento por parte de ella (pp.96-103) - ¡Ah! ¡La futura Madame Baterfly, la mujer desdeñada de Puccini ya está aquí!-. "Amor, paz, comodidad, inconmensurable contento... esa era la vida en el Jardín" (p.103). Y se convierten en científicos, el texto se vuelve divertida y paródicamente anacrónico (Ley de Adán de la precipitación de los Líquidos y otras...). Es ella la que piensa: ¿por qué animales como el león tienen caninos tan desarrollados si son hervívoros? Es una pena, un desperdicio... Viven felices, charlando y paseando, hasta que oyen la Voz del Señor del Jardín -sólo Adán la escuchó antes-. Ahora se pone en marcha un diálogo ágil y divertido pero calculado; Eva está buscando su justificación, el texto resalta la inocencia con que actúan:

"Era el Señor del Jardín, dijo, y le había ordenado que cultivara el Jardín y lo guardara, y había dicho que no debíamos comer del fruto de cierto árbol y que si lo comíamos seguro que moriríamos (...). Yo quería ver el árbol (...). Adán dijo que era el árbol de la ciencia del bien y del mal

- ¿El bien y el mal?

- Sí.
- ¿Qué es eso?

- ¿Qué es qué?

- Pues esas cosas. ¿Qué es el bien?

-No lo sé. ¿cómo iba a saberlo?

- Bueno, entonces ¿qué es el mal?

- Supongo que el nue es el mal?

- Supongo que es el nombre de algo, pero no sé de qué.

- Pero Adán, tienes que tener alguna idea de lo que es.

¿Por qué había de tener alguna idea? No he visto nunca el objeto ¿cómo iba a

formarme un concepto de él? ¿Qué noción tienes tú de él? (Twain: 2005, 113-114).

En una sociedad patriarcal es el hombre el oráculo, quien debe sacar las castañas del fuego. Con ironía, el texto hace ver que Adán siempre se lava las manos; por el contrario, Eva mucho más lanzada, toma la batuta: “iQue tontos somos! Comamos de él. Moriremos y entonces sabremos qué es y no nos preocupará más. Adán vio que era la idea correcta" (Twain: 2005, 115). Pero no llegan a comer la manzana -recurso interesante para mantener el suspense, aunque el lector occidental ya sabe cómo termina la historia- porque aparece un bicho raro tras el que corren y al que deben nombrar -están haciendo un diccionario-. El escritor disfruta con los anacronismos, incluido el que el texto sea un diario de nuestros primeros padres, lo que no deja de tener su ironía. Por cierto, que, una vez más se muestra la supremacía femenina; Eva se sabe utilizada, aunque siempre le da la vuelta:

“Es él quien está haciendo el Diccionario -eso cree-, pero he notado que soy yo la que hace el trabajo. Pero no importa, me gusta hacer cualquier cosa que me diga que haga, y en el caso del Diccionario lo hago con placer especial, porque le ahorra humillaciones, pobre chico. Su ortografía es muy poco científica" (Twain: 2005, 117).

El último tramo de esta autobiografía se centra en el nacimiento de Caín, una sorpresa, "lo tomé por un animal (...), algunos de sus rasgos eran humanos, pero no tenía los suficientes para justificar que lo clasificara científicamente -reparen en este término- bajo esa categoría" (Twain: 2005, 120). Triunfa el amor materno y debe luchar para protegerlo de un padre que cuando vuelve de cazar "sometió al niño a todas las incomodidades e inconveniencias que se pueda imaginar a fin de determinar qué clase de pájaro, reptil o de cuadrúpedo era" (Twain: 2005, 121). Es decir, Adán y Eva son dos chicuelos deslumbrados por la novedad rutilante de un mundo con inagotables sorpresas... él más brutito, ella con más sentido común. Este breve sumario (el nacimiento de Caín, su primer hijo) se ha desplegado en las primeras páginas -el diario de Adán- de modo divertidísimo con ironía, humor y extrañamiento -que es el concepto con que funciona el narrador, ponerse fuera y observar con asombro personas y cosas desde la otredad-; técnica que logra las páginas más divertidas:

"Lo hemos llamado Caín. Lo cogió mientras yo estaba poniendo trampas (...) se nos parece en algunos aspectos y puede que sea un pariente (...) un pez, quizá, 
aunque cuando lo puse en el agua para ver se hundió y ella se zambulló y lo sacó rápidamente antes de que el experimento tuviera la oportunidad de decidir la cuestión (....). No es un pez. No consigo averiguar qué es. Cuando no está satisfecho hace unos ruidos curiosos y atroces y cuando lo está dice $g u$ - $q u$. No es uno de los nuestros porque no anda. No es un pájaro porque no vuela (.). Si uno de los nuestros perque no anda. No tanto" (Twain: 2005, 26-27)

En resumen, el escritor norteamericano saca inmenso partido del viejo recurso de la extrañeza utilizado por Montesquieu en sus Cartes persannes y copiado por Cadalso en sus Cartas marruecas: el extranjero, niño o joven inocente, virginal, que se asombra de las incongruencias de la sociedad valorada desde los parámetros del sentido común del hombre racional. No obstante, lo que predica el texto es una sociedad armónica: la mujer se pliega, aunque se sepa más inteligente y utilizada; y el hombre, al que molesta su modo de ser -"habla y habla siempre"- se adapta también en pro de su conveniencia, porque "noto que me hace mucha compañía" y además en el trabajo "me será muy útil. Yo supervisaré" -dirá sin pudor alguno, bien instalado en una sociedad patriarcal (Twain: 2005, 23)-. La mujer obtendrá su recompensa por la vía amorosa, manipulando desde la recámara, organizando el mundo desde el espacio privado, ganándose el reconocimiento del varón quien, al final, en la tumba de Eva, colocará a modo de lápida, su tributo de amor y gratitud: "Allá donde estuviera ella estaba el paraíso" (Twain: 2005, 68).

Hemos hablado de Adán y Eva. El tercero en discordia es Satanás, según su diario no tan malvado, cuenta cómo dialoga con ellos, los compadece, trata de explicarles conceptos como el dolor, la muerte, el sentido moral. En cuanto a la famosa tentación comen porque quieren probarlo todo, no pueden hacer el mal, lo desconocen. El relato es un sumario casi desapasionado que matiza de nostalgia una enumeración caótica, síntesis de lo que se avecina tras ese momento cumbre en la historia de la humanidad:

\section{“¡Eva alcanzó una manzana!... ¡Oh, adiós Edén, adiós a tus inocentes alegrías, llegan la pobreza y el dolor, el hambre, el frío y el sufrimiento, la separación de los seres queridos, las lágrimas y la vergüenza, la envidia, el conflicto, la malicia y el deshonor, la vejez, el cansancio, el remordimiento... luego la desesperación y la plegaria para que nos liberen de la muerte a la que no importa que las puertas del infierno se abran de par en par tras ella!" (Twain: 2005, 139).}

Sospecho que se me echó encima el tiempo para hablar de Gioconda Belli y su novela El infinito en la palma de la mano. ¡Qué título -son versos de W. Blake- y portada tan bellas! Es la mujer, joven, bella y por supuesto desnuda, es decir, inocente, la que atisba un inmenso panorama de naturaleza verde y plácida, sentada en una inmensa mano ¿La mano del creador? Tal vez. El infinito -el mundo natural- se abre ante sus ojos con todas las posibilidades, pero ella misma es el infinito, un mar insondable. Esta novela profundiza en la psicología de los personajes, en el misterio del sueño, en el sentido de la vida y el dolor tras el desorden universal -gran cataclismo, terremoto de proporciones grandiosas, por cierto, copiado de Twain- que sigue al pecado original, al disfrute del higo -porque es un higo dulce el causante de todos los males, sensual, oloroso, compartido con toda la creación excepto el inmortal ave fénix-. También en común, Adán sigue a Eva por caballerosidad en el norteamericano; porque no quiere estar y quedarse sólo, sin ella, en la novela de la nicaragüense. Adán es desvalido, indeciso, más débil, se lamenta una y otra vez (Belli: 2008, 62,74, 123...), acusa a Eva de ser la causante de sus desgracias (Belli: 2008, 79, 88, 91...). Eva se defiende, es la inquieta, la de las preguntas inconformes lejos de la mansedumbre que caracteriza la vida en el Jardín, quien toma las riendas en las decisiones (Belli: 2008, 20, 22, 26, $60,137)$, quien comienza a pintar para sacarse la congoja (Belli: 2008, 143-144), en lo que puede interpretarse como una reescritura cultural de cuyo femenino/feminista. Me voy a centrar en dos cosas, muy brevemente: la relación con EloKim a través de la serpiente -porque Él casi nunca aparece-, es ella la portavoz, la que mediatiza y enseña lo que deben hacer los humanos tras la tentación y caída. Y, por fin, la pregunta inevitable: ¿es feminista esta obra?

Empecemos por el final: yo diría que es femenina y feminista -términos tan connotados, habría que matizar-. La mujer es el centro; es el otro lado de la historia el silenciado el que aquí explota. Es la mujer quien con su actuación responderá a las preguntas “¿Qué hacemos aquí?”, “¿Dónde está el Otro?” (Belli: 2008, 20) irresolubles para el varón. Ella es la predestinada: todavía en el Jardín y al borde del agua, tiene una visión -especie de Aleph- que sintetiza siglos y generaciones de hombres y mujeres:

... "un ojo salido de quien sabe dónde abrió sus párpados, la miró y al hacerlo la concedió ver a través de su tembloroso cristalino imágenes fascinantes y vertiginosas en las que ella mordía el higo y de ese minúsculo incidente brotaba una espiral gigantesca de hombres y mujeres efímeros y transparentes que se multiplicaban (...). La Historia, se dijo. La había visto. Era eso lo que empezaría si ella comía la fruta. Elokim quería que ella decidiese si existiría o no todo aquello. Él no quería hacerse responsable. Quería que fuese ella quien asumiese la responsabilidad" (Belli: 2008, 34-35).

Por eso se defiende de su pecado (Belli: 2008, 224), que según ella no es tal, lo único que hizo sin saberlo es cumplir la voluntad divina: gracias a la decisión de la mujer la historia se puso en marcha -le dirá una y otra vez a Adán-; al comer del árbol del conocimiento, hace algo que Elokim quería, que los hombres comenzaran a usar la libertad, se crearan y destruyeran (Belli: 2008, 28, 35, 39, 41, 49, 60, 78, 97, 224). La mujer es protagonista indiscutible de la vida y Eva se preguntará si vivir y dar vida es un privilegio o más bien un castigo.

Es una apuesta muy fuerte ¿feminista? Pues sí, concluiríamos... 
Pero es mucho más -y aquí mis dos preguntas se entrelazan-, yo la considero una novela posmoderna: la plasmación del sinsentido del mundo contemporáneo, la rebeldía del hombre de hoy frente a mitos, historias, dioses... que no comprende. La reiterpretación y relectura bíblica desde nuestro mundo laico: no hubo amor en la creación; Elokim crea por aburrimiento y se olvida después de ese mundo (Belli: 2008 $27,56,149,162,181)$ imperfecto en sus consecuencias, en el que entró definitivamente el mal -eso está en Borges, es un tópico en escritores del XX-. No queda nada del amor y la armonía neoplatónicas, recuperadas en el romanticismo, de esa visión del mundo como libro de Dios, perfecto y donde todo encaja, todo tiene sentido. En un momento concreto de la novela, Eva se enfrenta al Creador y le acusa de crueldad, le acusa de saber las consecuencias de la tentación y la caída desde siempre (Belli: 2008, 87). Desde estos planteamientos, ¿existen el Bien y el Mal? ¿Qué son en definitiva? (Belli: 2008, 62, $128,200 \ldots)$. Tampoco queda nada del amor cristiano en esta visión desesperanzada de un universo que va dando tumbos, sin sentido. Y paradójicamente, los hombres están solos, solos, Serpiente es el único ser que dialoga con ellos. Se ha cerrado el círculo, el desencanto posmoderno se impone en las páginas de una dura aunque bella historia de amor, la de los dos primeros habitantes, y es ese amor el que -como en Twainjustificará tanto dolor.

Modernidad/posmodernidad: dos épocas, dos filosofías, dos modos de enfrentarse a la libertad, la historia y el destino individual del ser humano. Dos literaturas para plasmarlo: a diferencia de la novela de Gioconda, el sentido de la creación que Twain pone en boca de la inteligente Eva es acorde a la ortodoxia cristiana. La creación tiene un sentido amoroso por parte de un Dios que, sin necesitar a los hombres para ser feliz, quiere compartir sus delicias con ellos -siempre según la Biblia-. Aunque le cueste más de un disgusto, porque su criatura se le rebela y Él voluntariamente, tomará forma humana para redimirla con su muerte en la cruz -y las teólogas saben bien que el Génesis se ilumina desde el Nuevo Testamento, en especial el prólogo al Evangelio de Juan-. Eva dirá:

"Al principio no comprendía por qué me habían hecho, pero ahora creo que es para averiguar los secretos de este mundo maravilloso, y ser feliz y dar las gracias al Dador de todas las cosas por haberlo inventado" (Twain: 2005, 63).

\section{REFERENCIAS BIBLIOGRÁFICAS}

Ainsa, F. Los buscadores de la utopía. Caracas, Monte Avila, 1977.

Belli, G., De la costilla de Eva. Managua, Nueva Nicaragua, 1986.

----. El infinito en la palma de la mano. Barcelona, Seix Barral, 2008.
----, “Adán y Eva vistos con ojos de mujer", en http://www.escritores vascos.com/old/?p=619. Revisado el 15 _III-2008.

Caballero, M., "La mujer en el Catecismo de la Iglesia Católica”, en Estudios sobre el catecismo de la Iglesia Católica. Madrid, Unión Editorial, 1996, pp. 195-222.

-----, "Género y literatura hispanoamericana", en Feminismo y multidisciplinariedad, coord. Helena Establier, revista Feminismo/s. Revista del Centro de Estudios sobre la mujer de la Universidad de Alicante, Alicante, núm. 1, 2003, pp. 103-116.

De Toro, A. y Gronemann, C. (eds.), Autobiographie revisited. Theorie ynd Praxis neuer autobiographischer Diskurse in der französischen, spanischen und lateinamerikanischen Literatur. Leipzig, Oms (Passagem) 2004.

Effel, J. y Cela, C. J., La novela de Adán y Eva. Barcelona, Ahr, formato caja con dibujos, 1968. Eça de Queiroz, Adán y Eva en el paraíso. Madrid, Novelas y Cuentos, 1930.

Lejeune, P., Le pacte autobiographique. Paris, Seuil, 1975.

----, Pour l'autobiographie. Chroniques. Paris, Seuil, 1998

López de Haro, R., Adán y Eva y yo. Barcelona, Araluce, 1939.

Muñoz, F., Las colinas del Edén. Barcelona, Plaza y Janés, 2006.

Nothomb, A., Ni de Eva ni de Adán. Barcelona, Anagrama, 2009.

Pozuelo Yvancoz, J. M., De la autobiografía. Teoría y estilos. Barcelona, Crítica, 2006.

Twain, M., El diario de Adán y Eva. Madrid, Valdemar, 2005. 